\title{
The Functional Anatomy of Impulse Control Disorders
}

\author{
Catharina C. Probst • Thilo van Eimeren
}

Published online: 21 August 2013

(C) The Author(s) 2013. This article is published with open access at Springerlink.com

\begin{abstract}
Impulsive-compulsive disorders such as pathological gambling, hypersexuality, compulsive eating, and shopping are side effects of the dopaminergic therapy for Parkinson's disease. With a lower prevalence, these disorders also appear in the general population. Research in the last few years has discovered that these pathological behaviors share features similar to those of substance use disorders (SUD), which has led to the term "behavioral addictions". As in SUDs, the behaviors are marked by a compulsive drive toward and impaired control over the behavior. Furthermore, animal and medication studies, research in the Parkinson's disease population, and neuroimaging findings indicate a common neurobiology of addictive behaviors. Changes associated with addictions are mainly seen in the dopaminergic system of a mesocorticolimbic circuit, the so-called reward system. Here we outline neurobiological findings regarding behavioral addictions with a focus on dopaminergic systems, relate them to SUD theories, and try to build a tentative concept integrating genetics, neuroimaging, and behavioral results.
\end{abstract}

Keywords Behavioral addictions · Pathological gambling · Binge eating · Compulsive buying · Hypersexuality . Substance use disorders $\cdot$ Mesocorticolimbic circuit $\cdot$ Reward system · Dopamine · Parkinson · Parkinson's disease · Neurobiology $\cdot$ Risk factors · Impulse control disorders · Functional anatomy

This article is part of the Topical Collection on Neuroimaging

C. C. Probst · T. van Eimeren

Department of Neurology, Christian Albrechts University, Kiel, Germany

C. C. Probst

e-mail: c.probst@neurologie.uni-kiel.de

C. C. Probst $\cdot$ T. van Eimeren $(\square)$

Department of Neurology, University Medical Center

Schleswig-Holstein, Kiel Campus, Arnold-Heller-Str. 3,

24105 Kiel, Germany

e-mail: tvaneimeren@gmail.com

\section{Introduction}

In the past decade, many exciting findings have shed light on a new neurobiological understanding of impulsive-compulsive behavioral disorders, such as pathological gambling. Above all, the important role of the neurotransmitter dopamine has been highlighted. About $14 \%$ of patients with Parkinson's disease (PD) receiving dopaminergic medication develop impulsivecompulsive disorders, such as pathological gambling, hypersexuality, compulsive eating/binge eating, and compulsive buying [1•]. Albeit less prevalent, these disorders also occur in the general (non-PD) population, are sometimes referred to as "disorders in the impulsive-compulsive spectrum", "impulse control disorders" (ICDs), or "behavioral addictions," and can be classified in DSM-IV-TR as ICDs, even though only pathological gambling has specified criteria [2]. It was found that, despite the different labeling, disorders such as pathological gambling, hypersexuality, binge eating, excessive shopping, and excessive Internet use share some essential features with substance use disorders (SUDs) [3]. Behaviorally, substances as well as behavioral addictions are characterized by a fixation on the particular drug/behavior and sometimes disregard for natural reinforcers. Other similarities are the craving to consume the substance or execute the behavior in phases of abstinence and the inability to stop the harmful behavior [3]. There is ample evidence that these excessive and reinforcing behaviors involve the dopaminergic "reward system," as do all substances of abuse (for a review, see [4]). Owing to these similarities in phenomenology and neurobiology, it has been proposed to classify several of the ICDs as behavioral addictions in DSM-V, yet only pathological gambling has been moved to the "addictions and related disorders" section of DSM-V [4].

Efficient therapy and prevention of ICDs rely on a good understanding of how these pathological behaviors develop. One important starting point is the common neurobiology and the similarities to addiction. Therefore, we will start by describing the neuroanatomy of reward processing and its alteration in 
substance and behavioral addictions. Subsequently, we will try to outline predisposing and associating factors regarding behavioral addictions in the PD and non-PD populations, focusing on neuroimaging and dopamine. Finally, we will describe neurobiological principles of a dopaminergic endophenotype that may be at risk of develop ICDs/behavioral addictions.

\section{The Addiction Circuitry}

There has been extensive research on the neurobiological basis of SUDs (for a review, see [5]). Here, we outline neuroanatomical circuits involved in the development and maintenance of substance addictions as well as behavioral addictions.

\section{The Neuroanatomy of the Mesocorticolimbic "Reward" System}

Drugs and other rewarding stimuli act as reinforcers on a mesocorticolimbic circuit, the so-called reward system, comprising the ventral striatum [VS; including the nucleus accumbens (NAcc)], the orbitofrontal cortex (OFC), the anterior cingulate cortex (ACC), the amygdala, and the hippocampus [5] (but see also [6]). Novel stimuli, natural reinforcers such as eating and sex, and nonnatural reinforcers lead to a phasic release of dopamine from the ventral tegmental area to the NAcc, the amygdala, and the hippocampus [7]. This dopaminergic signal likely reflects salience attribution and promotes associative learning. The amygdala and the OFC presumably play a key role in associating reward-predicting cues with the positive emotions elicited by the actual reward [8]. The OFC is additionally involved in encoding and updating the (relative) reward value [8]. Dopaminergic neuromodulation in the midbrain seems to enhance hippocampus-dependent long-term memory formation so that reward-related stimuli and contexts are reliably recognized in later situations [7]. The ACC, on the other hand, is hypothesized to link rewards with actions and thus has a gating role in action selection following reward cues [9]. In a healthy brain, reward-directed behavior is adaptively controlled by inhibitory influences of the prefrontal cortex (PFC). Here, different sensory inputs, memories, goals, and physiological states (e.g., nutrient supply) have to be integrated to entail an adequate performance [10]. Via the OFC and ACC, top-down influences reach mesolimbic areas again and regulate reward-seeking motivation [9].

Although processing in the mesocorticolimbic circuit predominantly relies on dopaminergic transmission, other neurotransmitter systems also play significant roles. It is assumed that the "liking" of rewards is conveyed by $\mu$-opioid stimulation and closely interacts with the dopaminergic system in the NAcc and ventral pallidum [11]. Furthermore, coactivation of dopamine $\mathrm{D}_{1}$ receptors and NMDA systems within corticolimbic striatal circuits may be necessary for adaptive reward learning [12].
GABAergic projections from the tail of the ventral tegmental area/rostromedial tegmental nucleus to the nearby ventral tegmental area and substantia nigra seem to act as a major brake for dopaminergic systems [13].

\section{An Altered System - the Addiction Circuitry}

Substances of abuse can be seen as strong synthetic reinforcers. They cause a stronger release of dopamine that does not habituate as fast as with natural rewards [5, 14]. Dopaminergic signals in the midbrain are thought to reflect salience attribution and therefore imprint an incentive value on addictive substances and motivate appetitive behavior toward associated stimuli [5]. Heightened salience attribution is reflected by stronger activation of the reward system following drugassociated cues (e.g., an alcoholic seeing a bottle of beer) [15]. In the terminology of conditioning, cues become conditioned stimuli for the unconditioned stimulus (i.e., substance or behavior). There are fewer studies regarding cue reactivity in behavioral addictions, and the results are conflicting and not always comparable with those of SUD studies [16-19]. This may be due to diverging methods and cues [20]. In substance addiction as well as behavioral addiction, reaction to the conditioned stimulus is associated with "wanting" or "craving" for the unconditioned stimulus $[5,18,21]$. Repeated exposure to an unconditioned stimulus presumably leads to overactivation of the mesolimbic dopaminergic system with reduced influence of inhibitory frontal brain areas [9] (see Fig. 1). In line with this suggestion, subjects with substance addictions and/or behavioral addictions are characterized by generally diminished impulse control, as the term "impulse control disorder" (ICD) implies [22-24]. When tempted, the motivation to take the drug or carry out a behavior beats the efforts to control the addictive behavior. During the addiction process, the initially arbitrary behavior eventually becomes more habitual. SUD-related theories suggest that during habit formation, activation caused by the conditioned stimulus shifts from the shell of the NAcc to its core and finally to dorsal parts of the striatum and associative as well as sensorimotor corticostriatal circuits [7]. Also in ICDs, there have been findings that suggest such a transition [25].

\section{Theories on the Development of Addiction}

A recent review has outlined the main theories on the development of SUDs [26]. The reward deficiency hypothesis states that a certain genetic variation leads to a reduced $\mathrm{D}_{2}$ receptor density in the limbic system [27]. Therefore, vulnerable individuals feel uncomfortable and in need of strong reinforcers to get the dopamine level back to normal and relax [27]. Robinson and Berridge [15], however, stress the role of salience attribution in addiction development and postulate that drugassociated dopamine surges sensitize the reward system during repeated drug use. The result is a hypersensitivity to incentive 


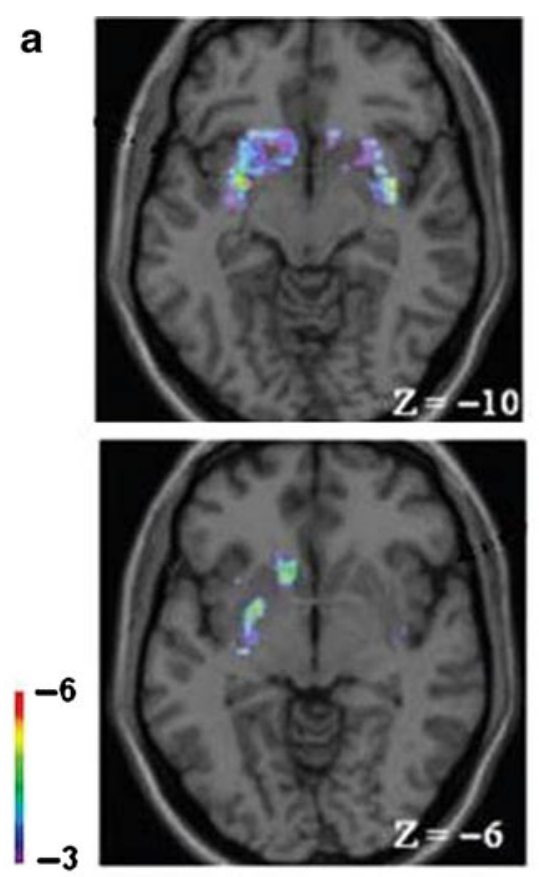

Fig. 1 Heightened striatal dopamine release during gambling in Parkinson's disease (PD) with pathological gambling (a) [35] and reduced activation of the orbitofrontal cortex (OFC) and rostral cingulate zone (RCZ) in pathological gambling after dopamine (DA) administration (b) [91 •]. a Ventral striatal DA release (indexed by a reduction of $\left[{ }^{11} \mathrm{C}\right]$ raclopride binding potential) during gambling as compared with that

motivational effects of drugs and drug-associated stimuli. Even though there is much evidence in favor of the sensitization theory, it does not explain why some are more vulnerable than others. Goldstein and Volkow [28] developed the impaired response inhibition and salience attribution (I-RISA) model of addiction which integrates enhanced salience attribution and impaired inhibition. Like Blum et al. [27], they hypothesize that $\mathrm{D}_{2}$ receptor deficiency is initially responsible for drug use and reward-seeking behavior [28].

In this section, we drew a schematic picture of the structures and circuitries involved in reward processing and addiction. In the following sections, we will highlight neurobiological findings in behavioral addictions and relate them to addiction development theories.

\section{Factors Associated with the Development of Behavioral Addictions}

Every human possesses a reward system, but not everyone is responsive to rewards to the same degree. Quite a lot of people gamble from time to time, and all of us eat, shop, or have sex more or less frequently. But who will become addicted? An overview of the factors that are thought to influence the genesis and development of behavioral addictions is given in Fig. 2.

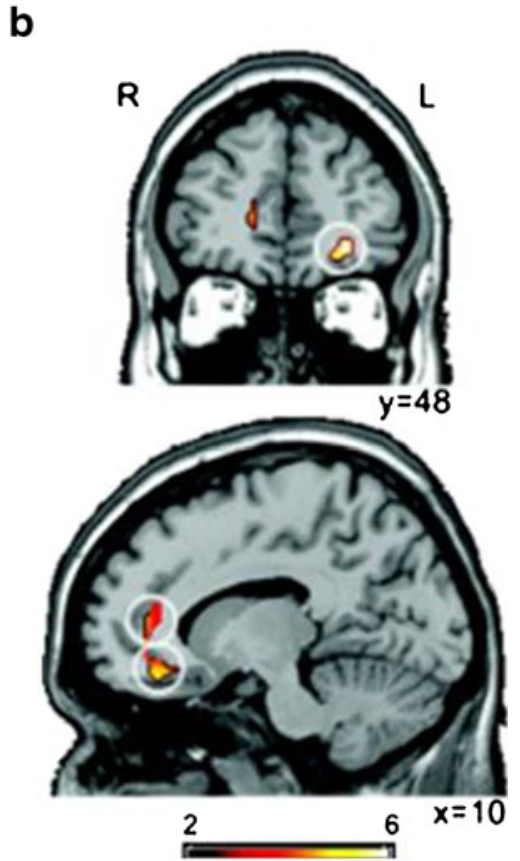

in a control task in PD patients with (top) and without (bottom) pathological gambling. $\mathbf{b}$ Differential effect of medication on brain activity in PD gamblers compared to controls. Gamblers showed a significant dopamine-induced reduction in the left lateral OFC (top) and right RCZ (bottom). (a With permission from: Steeves et al. [35]; b with permission from van Eimeren et al. [91•])

\section{Genetics}

Estimations of heritability in SUDs range from 40 to $70 \%$ [29]. Research in the field of behavioral addictions is less extensive and concentrates on pathological gambling. One large study showed that genetic influences account for $37-55 \%$ of the variability in pathological gambling [30]. Two other studies, however, found lower [31] or considerably higher [32] heredity rates. There are several reasons for why the examination of a genetic influence of polymorphisms on the development of ICDs is highly complex and multidimensional. First, the expression and influence of genes is partly dependent on environmental influences and lifespan (epigenetics) [29]. Second, the findings only indicate that some polymorphisms affect the development of traits and/or the availability of neurotransmitters, which in turn predict (behavioral) addictions to a certain extent. Third, polymorphisms frequently promote behavioral addictions in interaction with other polymorphisms.

For a detailed discussion of the associations between genetic predispositions and ICDs in PD and non-PD populations, we refer to two recent reviews that provide an overview of genetics in behavioral addictions [33, 34]. Briefly, the studies suggest genetic susceptibility mainly regarding polymorphisms influencing dopaminergic transmission, for example, the dopamine transporter polymorphism SLCA3 or the $\mathrm{D}_{2}$ receptor polymorphism Taq1A. But also genetic variations determining 


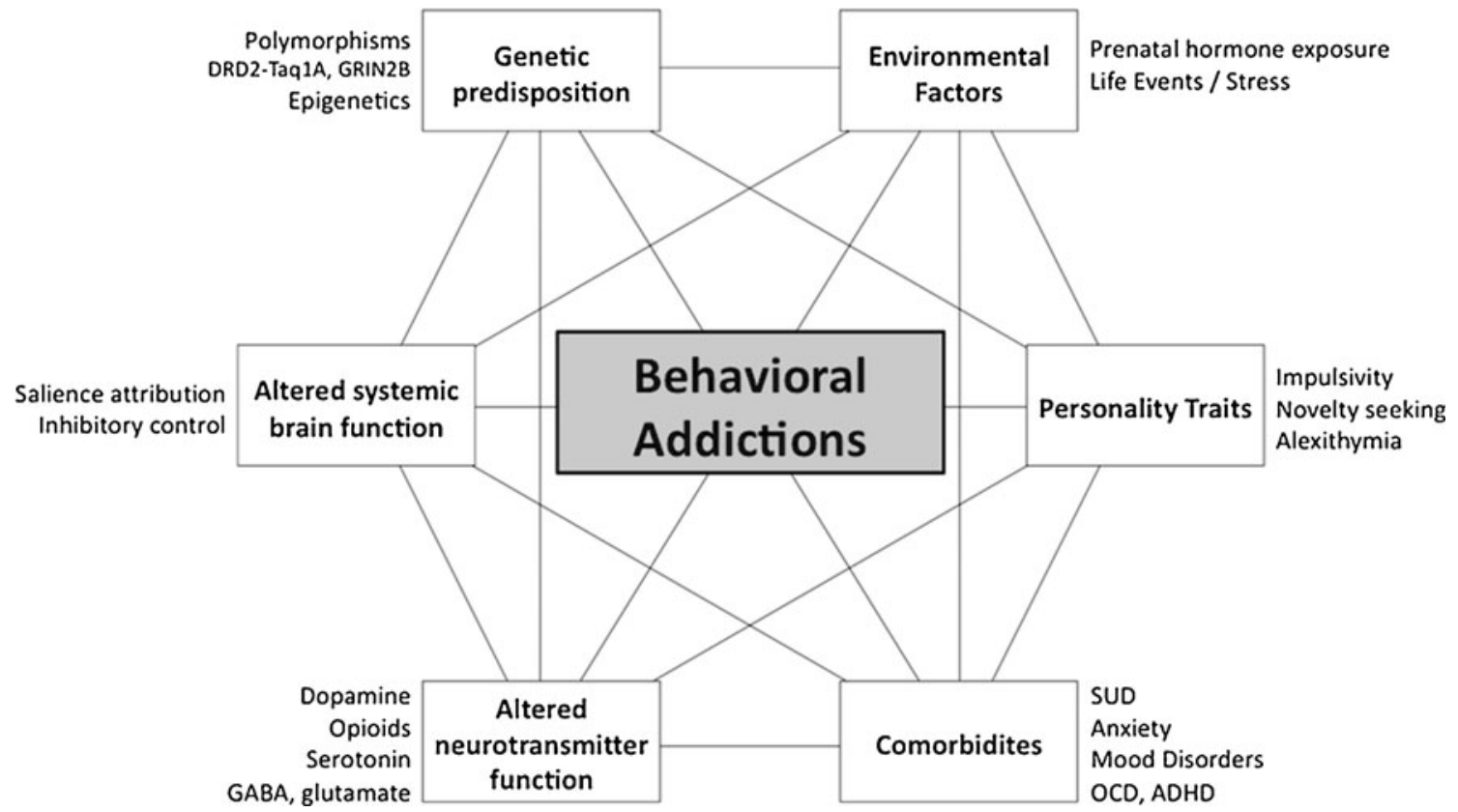

Fig. 2 Interacting factors associated with the development of behavioral addictions. $A H D H$ attention deficit-hyperactivity disorder, $O C D$ obsessivecompulsive disorders, $S U D$ substance use disorders

catecholaminergic, serotonergic, glutamatergic, and opioid systems have been shown to be predisposing for ICDs and/or associated traits.

\section{Neurotransmitters}

As mentioned previously, the availability and functioning of neurotransmitters depend on gene-environment interaction. Some of the resulting endophenotypes are apparently more prone to develop (behavioral) addictions than others. With a focus on dopamine, this section provides an overview of altered baseline neurotransmitter function in behavioral addictions.

\section{Dopamine}

Owing to the lack of prospective longitudinal studies, it is often difficult to determine if neurobiological variations precede or follow the development of behavioral addictions. Nonetheless, findings indicate that preexistent, partly genetically determined, dopaminergic abnormalities lead to pathological behaviors which in turn cause a further disbalance in the dopaminergic system. Studies focusing on the $\mathrm{D}_{2}$ receptor gene suggest that the A1 allele of the Taq1A polymorphism creates a condition that is characterized by reduced availability of $\mathrm{D}_{2}$ receptors in the striatum [27]. Additionally, there are findings that pathological gamblers and people with pathological overeating or Internet addiction show reduced $\left[{ }^{11} \mathrm{C}\right]$ raclopride baseline binding potential in the striatum [35-37]. However, PET results may indicate either a functional downregulation of dopamine transporters or receptors or else higher synaptic dopamine levels. Thus, it remains unclear whether there is a basal hypodopaminergic state as proposed by the reward deficiency hypothesis or rather a hyperdopaminergic state as suggested by the sensitization hypothesis [15]. In contrast to these findings, other studies in pathological gambling $[38,39 \bullet \cdot]$ and a study with PD patients with ICDs did not find different baseline binding compared with controls $[40 \bullet \bullet$.

\section{Other Neurotransmitters}

Although one can assume that other neurotransmitter functions are altered in addiction [24], evidence is often limited to preclinical or medication studies in SUDs.

Opioid antagonist therapy can be an effective treatment in several ICDs, which may be based on midbrain $\mu$-opioid receptor stimulation causing inhibition of GABA and consequent dopamine release [41-44]. Regarding serotonin and ICDs, there are mixed results regarding treatment studies with serotoninergic medication [24]. However, Cools et al. [45] propose that although dopamine serves to promote behavioral activation to seek rewards, serotonin serves to inhibit actions when punishment may occur. Preclinical studies on SUDs indicate that altered glutamatergic transmission from the PFC to the NAcc results in compulsive focusing of behavior on drug-associated stimuli [46]. There is only limited evidence from preclinical trials and medication studies that glutamatergic and GABAergic medication effectively treats (behavioral) addictions [47-50].

Currently, the contribution of neurotransmitters in behavioral and substance addictions is best understood for dopamine. 


\section{Neuroimaging Findings}

Here, we highlight neuroimaging findings of altered brain functions and aberrant behavior related to reward processing in behavioral addictions. Since dopamine is presumed to be involved in numerous key functions in reward processing, we will focus on a possible dopaminergic basis.

\section{Reward and Punishment Reactivity}

Altered reward sensitivity due to changes in dopamine function is one main component of all addiction theories, but is still poorly understood [51]. Summarizing the results is difficult since there is a multitude of different study designs, often lacking proper discrimination between simple reward perception and various phases of reward learning.

Unpredicted rewards and reward prediction cues elicit a phasic increase in striatal dopaminergic signal, whereas an anticipated but not obtained reward (also called negative prediction error) or an unpredicted loss is followed by a decrease in tonic striatal dopamine receptor stimulation [51, 52]. Regular reward sensitivity would therefore yield activation correlating with reward prediction and its errors, i.e., activation for unpredicted rewards and reward cues and deactivation for omitted rewards or losses.

Predicted rewards seem to elicit less activation mainly in the ventromedial PFC in patients with ICDs as measured with the monetary incentive delay task in two studies [53, 54 $]$. Regarding unpredicted reward, a study found that all participants showed greater VS activity in response to reward than to punishment, but pathological gamblers had lower differential activation in the right striatum than controls [25]. It is, though, not clear if this difference in reward sensitivity is due to a blunted reaction to rewards or to losses or both. Notably, dopamine agonists were shown to decrease reward sensitivity in PD patients mainly caused by abolished deactivation following unexpected losses [55]. People with an Internet addiction showed enhanced OFC activation following unpredicted rewards but decreased ACC activation after losses [56].

Behaviorally, altered reward sensitivity leads to modified reinforcement learning. Several studies showed that individuals with pathological gambling or binge eating disorder showed impaired reward and punishment learning [57-59]. Performance in a card game with implicit reward and punishment learning correlates with activation in a neural circuitry involving the dorsolateral PFC, insula, posterior cingulate cortex, OFC, ventromedial PFC, VS and ACC/supplementary motor area in healthy individuals. There are only a few neuroimaging studies assessing reinforcement learning in behavioral addictions. One PET study in pathological gambling found higher dopamine release in the VS accompanied by higher excitement despite impaired performance [60]. Power et al. [61] showed that pathological gambling exhibited increased activation in the right caudate, right $\mathrm{OFC}$, and amygdala/hippocampus during highrisk trials, which could indicate greater salience of monetary rewards.

Some results indicate that people with behavioral addictions show a blunted response to predictable rewards. However, when it comes to learning, the results propose reduced sensitivity to losses and a constant or even heightened sensitivity to gains. Regarding the addiction theories, these findings are in line with the sensitization theory, since it predicts a hypersensitive mesolimbic dopaminergic system, i.e., stronger salience attribution mechanisms. Blunted response to predicted rewards would concord with the reward deficiency hypothesis; reduced sensitivity to losses, however, would not.

\section{Cue Reactivity}

In accordance with the sensitization theory and findings in SUDs $[5,15]$, several studies of behavioral addictions show enhanced mesocorticolimbic reactivity to related cues that is linked to a feeling of craving or wanting. In PD patients with ICDs in comparison with those without ICDs, O'Sullivan et al. [40••] found greater striatal dopamine release following related cues in contrast to neutral cues. Hypersexual PD patients receiving and not receiving dopaminergic medication showed heightened activation in response to visual sexual cues in the limbic cortex, paralimbic cortex, temporal cortex, occipital cortex, somatosensory cortex, and PFC compared with PD patients without ICD [62]. Increased activity in the ACC, posterior cingulate cortex, OFC, and VS correlated positively with subjective sexual desire.

Other studies of ICDs showed increased dopamine release in dorsal striatal areas or activation in the frontal, occipital, and parahippocampal cortices in response to cues [63-66]. Conversely, one functional MRI study using videos of gambling scenarios found decreased activity in the PFC and OFC, caudate/basal ganglia, and thalamus of subjects with pathological gambling compared with controls [18].

Two recent functional MRI studies with non-PD gamblers and subjects with binge eating disorder also provide contrasting results since they found decreased activation in the VS during anticipation of both gains and losses [54•, 67]. This might be because these studies implemented designs with cues predicting directly following reward (e.g., the monetary-incentive delay task), whereas the studies mentioned before used stimuli associated with addictions (e.g., food pictures for binge eaters).

To summarize, the results are heterogeneous but most studies suggest increased cue reactivity in the striatum and/ or PFC, similarly to SUDs.

\section{Probability and Delay Discounting}

As for SUDs, patients with ICDs show heightened risk taking/ probability discounting, e.g., going for a larger but less probable 
reward, and not for the smaller but more likely one [68-73], and altered delay discounting, i.e., choosing immediate smaller rewards over delayed larger ones [71, 74-77]. PD patients with ICDs, however, did not differ from controls in one study [78]. Both phenomena are probably related to altered reward sensitivity and disinhibition (lack of top-down control) [79]. Hence, brain areas included in valuation (ventromedial PFC, OFC, and VS) and cognitive control (lateral PFC and ACC) might be malfunctioning when abnormalities in delay or probability discounting occur as found in addiction [79]. One study found that activation in the VS and OFC for probabilistic rewards correlated less with subjective value in gamblers compared with controls [71]. Concordantly, PD patients with ICDs receiving dopamine agonists had less VS activation associated with explicit risk taking [70]. In delay discounting, however, activation in VS and OFC correlated stronger with subjective value in gamblers compared to controls [70].

To summarize, there is evidence that probability and delay discounting are altered in ICDs. Moreover, neuroimaging studies suggest altered activity in the OFC and VS in ICDs during discounting.

\section{Impulsivity/Disinhibition and Perseveration}

Impulsivity and disinhibition are often used synonymously when speaking of PFC-mediated top-down control [80]. Within this definition, impaired inhibition is seen in most SUDs and is associated with a hypoactive dorsal ACC and dorsolateral PFC [9, 81]. Pathological gamblers and PD patients with ICDs also show impairments in tasks such as the stop-signal task, go/no-go paradigms, and the Stroop task that involve inhibitory control [58, 81-84]. But there are also studies that did not find any behavioral differences between gamblers or Internet addicts and controls [85-88] or PD patients with ICDs and PD controls [89]. As to differences in brain activity, findings indicate reduced activity in the ventromedial or dorsomedial PFC [85, 90] (but see [88]). Stressing the role of dopamine, one study found that during a card game with probabilistic feedback, dopaminergic medication deactivated brain areas implicated in impulse control specifically in PD patients with pathological gambling [91•]. This concords with the idea that the effect of dopaminergic medication may depend on different baseline dopamine levels in ICD patients and controls (Fig. 3) [92].

Another phenomenon often associated with substance and behavioral addictions is response perseveration [84, 93, 94], i.e., the inability to change behavior even though this would be adequate. In healthy subjects, reversal learning, i.e., adequate adaption of behavior, recruits the ventrolateral PFC. Compatibly, one study found lower responsiveness of the right ventrolateral PFC during winning and losing money associated with response perseveration in a reversal learning task in pathological gamblers [95].
Similarly to disinhibition, perseveration has been linked to altered dopaminergic and serotoninergic function [45]. However, perseveration in reversal learning is often assessed with tasks that simultaneously measure risk taking or disinhibition. Thus, it is unclear whether these impairments can be disentangled.

\section{Traits, Comorbidities, and Life Events}

Traits related to substance and behavioral addiction in PD and non-PD populations include trait impulsivity and novelty and sensation seeking $[3,78]$. These traits are not independent of the aforementioned phenomena, since impulsivity and novelty seeking are closely linked to dopaminergic and serotonergic transmitter systems [96-98].

As for comorbidities, SUDs, depression, bipolar disorder, obsessive-compulsive disorder, anxiety disorders, and attention deficit-hyperactivity disorder are commonly seen together with behavioral addictions in PD and non-PD populations $[3,78]$. We recently found that ICDs in PD patients are-like in the non-PD population [99-101] - linked to alexithymia (the inability to identify and describe one's feelings) (K.S. Goerlich, C.C. Probst, L.M. Winter, K. Witt, G. Deuschl, B. Möller, and T. van Eimeren, 2013, unpublished data).

Environmental factors such as prenatal influences and critical life events are not to be disregarded as risk factors for the development of behavioral addictions. Increased fetal testosterone level, for example, has been associated with greater reward responsiveness in the striatum and increased behavioral approach tendencies in children [102]. Stressful life events in early childhood have been found to predict impulsivity [29]. Stress exposure in older age is known to play a key role in the occurrence of addiction and relapse, among others means by altering dopaminergic transmission [29].

\section{Synopsis of the Findings}

Before we summarize the findings, we need to acknowledge some general limitations. First, there are very few neuroimaging studies with patients with compulsive shopping or sexual behavior, so the evidence primarily builds on pathological gambling and to a lesser degree on Internet addiction and binge eating. Furthermore, there is a great lack of longitudinal studies of behavioral addictions. As a consequence, we do not know if the findings are triggers or consequences.

In summary, the data on behavioral addiction show a pattern similar to the neurobiology in SUDs. The findings indicate a lower dopamine receptor binding in the striatum [35-37], reflecting either a reduced receptor density or a heightened dopamine level. The blunted response to predicted rewards might be a sign of reduced sensitivity to "normal" rewards, or might stem from an increased baseline activity [53, 54•]. Heightened activation of the mesocorticolimbic system 


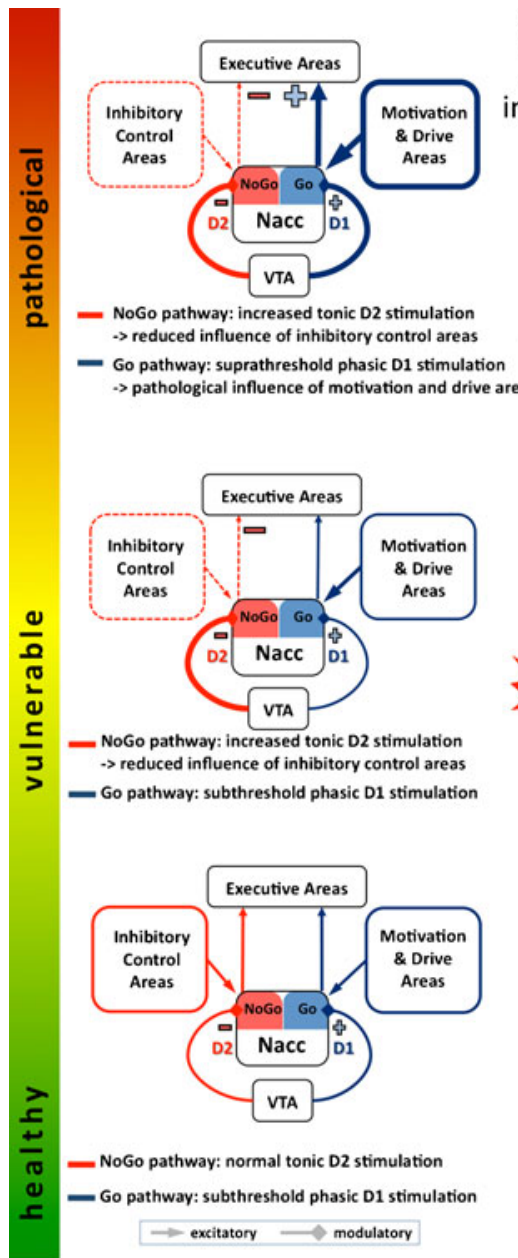

Fig. 3 A model of striatal DA level and subsequent influence of appetitive and inhibitory areas on executive control. Right panel, dotted line normal tonic and phasic DA release from the ventral tegmental area (VTA) to the nucleus accumbens (Nacc). Left panel, bottom the influences of inhibitory and appetitive areas are well balanced and adequately regulated. Right panel, solid line 1 vulnerable individuals have an

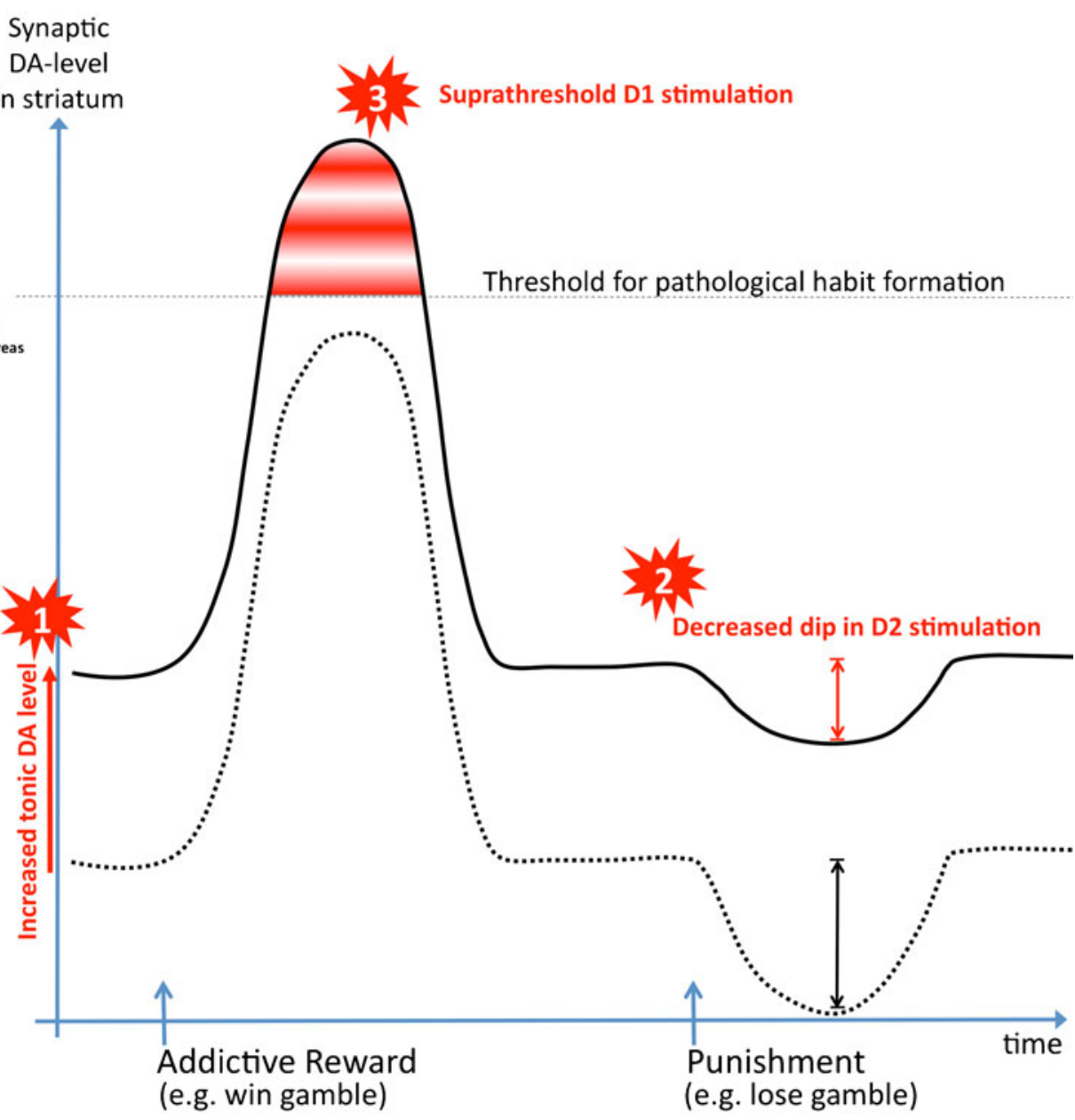

increased tonic DA level, leading to reduced influence of inhibitory control areas via increased $\mathrm{D}_{2}$ receptor activation (left panel, middle) $[58,81-84,91 \bullet] ; 2$ increased $\mathrm{D}_{2}$ receptor activation interferes with the dip following punishments [55]; 3 adequate reinforcing stimuli now lead to suprathreshold $D_{1}$ receptor stimulation, which drives the formation of pathological habits $[40 \bullet \cdot]$ following addiction-related cues $[40 \bullet, 56,62-66]$ speaks for a dopaminergic hypersensitivity. Reduced loss sensitivity and slower loss learning rates $[55,56,103]$ indicate a lack of a tonic dopamine level dip that usually appears during punishment. Additionally, subjects with behavioral addictions show impairments in inhibition and reversal learning tasks correlating with reduced activity in the ventrolateral and dorsolateral PFC [58, 81-85, 90]. Altered reward sensitivity as well as impaired topdown control also correlate with heightened risk taking and delay discounting [68-77].

All in all, the results mainly point to a pattern of heightened salience attribution and impaired inhibition as proposed by the I-RISA model of SUDs [28]. The question why some people develop ICDs and some do not still remains open. Prevailing evidence suggests a specific dopaminergic at-risk endophenotype (see Fig. 3): considering models of phasic and tonic dopamine functioning in the striatum and the PFC $[92,104]$, one could hypothesize that individual predisposition implicates heightened tonic dopamine levels in the striatum [33]. Tonic dopamine predominantly activates $\mathrm{D}_{2}$ receptors, whereas phasic dopamine stimulates $\mathrm{D}_{1}$ receptors [104]. Augmented tonic dopamine levels would explain prefrontal deficits in behavioral addictions, since an increasing tonic $\mathrm{D}_{2}$ stimulation has been shown to attenuate PFC inputs and was correlated with reduced PFC activity [5, 104]. Punishment, however, would not lead to sufficient reduction of tonic dopamine levels and hence hinder punishment learning. Suprathreshold phasic bursts following particularly strong reinforcers would thus promote habit formation. The results of studies in the PD population support the importance of an increased tonic dopamine level, since dopamine agonists primarily raise the tonic dopamine level.

Of course, this model is a gross simplification, not only with regard to dopaminergic transmission, but also because it disregards contributions of other neurotransmitters. Still, this 
model of a dopaminergic at-risk endophenotype is based on empirical neurobiological evidence and may inform future research and development of therapeutic strategies.

\section{Conclusions and Future Directions}

Opioid systems have to be looked at more closely, since they mediate hedonic experience, interact with dopaminergic systems, and may play a critical role in the individual preferences that lead to a specific addiction. In line with this, the complex interaction of the neurotransmitter systems involved in addiction should be a crucial aspect of future research. Finally, we need good longitudinal studies to disentangle triggers from consequences. Here, highly anticipated results of international initiatives (e.g., IMAGEN, http://www.imagen-europe.com) will hopefully deliver important answers.

Acknowledgment Thilo van Eimeren has received grant support from the Leibniz Association.

\section{Compliance with ethics Guidelines}

Conflict of Interest Catharina C. Probst declares that she has no conflict of interest.

Thilo van Eimeren has been a consultant for the CHDI Foundation, is employed by the German government, and has received travel/ accommodation expenses covered by several research organizations.

Human and Animal Rights and Informed Consent This article does not contain any studies with human or animal subjects performed by any of the authors.

Open Access This article is distributed under the terms of the Creative Commons Attribution License which permits any use, distribution, and reproduction in any medium, provided the original author(s) and the source are credited.

\section{References}

Papers of particular interest, published recently, have been highlighted as:

- Of importance

-. Of major importance

1. - Weintraub D, Koester J, Potenza MN, Siderowf AD, Stacy M, Voon V, et al. Impulse control disorders in Parkinson disease: a cross-sectional study of 3090 patients. Arch Neurol. 2010;67:58995. This is the largest epidemiological study on ICDs in PD. It still represents the best available evidence for the relationship between dopaminergic medication and ICDs in PD.

2. Task Force on DSM IV, American Psychiatric Association. Diagnostic and statistical manual of mental disorders: fourth edition text revision DSM-IV-TR. Washington: American Psychiatric Association; 2002.

3. Grant JE, Potenza MN, Weinstein A, Gorelick DA. Introduction to behavioral addictions. Am J Drug Alcohol Abuse. 2010;36:233-41.
4. Holden C. Behavioral addictions debut in proposed DSM-V. Science. 2010;327:935.

5. Volkow ND, Wang G-J, Fowler JS, Tomasi D. Addiction circuitry in the human brain. Annu Rev Pharmacol Toxicol. 2012;52:321-36.

6. Ikemoto S. Brain reward circuitry beyond the mesolimbic dopamine system: a neurobiological theory. Neurosci Biobehav Rev. 2010;35:129-50.

7. Everitt BJ, Robbins TW. Neural systems of reinforcement for drug addiction: from actions to habits to compulsion. Nat Neurosci. 2005;8:1481-9.

8. Dolan RJ. The human amygdala and orbital prefrontal cortex in behavioural regulation. Philos Trans R Soc B Biol Sci. 2007;362: 787-99.

9. Goldstein RZ, Volkow ND. Dysfunction of the prefrontal cortex in addiction: neuroimaging findings and clinical implications. Nat Rev Neurosci. 2011;12:652-69.

10. Miller EK, Cohen JD. An integrative theory of prefrontal cortex function. Annu Rev Neurosci. 2001;24:167-202.

11. Smith KS, Berridge KC. Opioid limbic circuit for reward: interaction between hedonic hotspots of nucleus accumbens and ventral pallidum. J Neurosci. 2007;27:1594-605.

12. Kelley AE, Berridge KC. The neuroscience of natural rewards: relevance to addictive drugs. J Neurosci. 2002;22:3306-11.

13. Barrot M, Sesack SR, Georges F, Pistis M, Hong S, Jhou TC. Braking dopamine systems: a new GABA master structure for mesolimbic and nigrostriatal functions. J Neurosci. 2012;32:14094-101.

14. Chiara GD. A motivational learning hypothesis of the role of mesolimbic dopamine in compulsive drug use. J Psychopharmacol. 1998;12:54-67.

15. Robinson TE, Berridge KC. The incentive sensitization theory of addiction: some current issues. Philos Trans R Soc B Biol Sci. 2008;363:3137-46.

16. Ko C-H, Liu G-C, Hsiao S, Yen J-Y, Yang M-J, Lin W-C, et al. Brain activities associated with gaming urge of online gaming addiction. J Psychiatr Res. 2009;43:739-47.

17. Van Holst RJ, van den Brink W, Veltman DJ, Goudriaan AE. Why gamblers fail to win: a review of cognitive and neuroimaging findings in pathological gambling. Neurosci Biobehav Rev. 2010;34:87-107.

18. Potenza MN, Steinberg MA, Skudlarski P, Fulbright RK, Lacadie CM, Wilber MK, et al. Gambling urges in pathological gambling: a functional magnetic resonance imaging study. Arch Gen Psychiatry. 2003;60:828-36.

19. Gearhardt AN, Yokum S, Orr PT, Stice E, Corbin WR, Brownell KD. Neural correlates of food addiction. Arch Gen Psychiatry. 2011;68:808-16.

20. Leyton M, Vezina P. On cue: striatal ups and downs in addictions. Biol Psychiatry. 2012;72:e21-2.

21. Pelchat ML, Johnson A, Chan R, Valdez J, Ragland JD. Images of desire: food-craving activation during fMRI. Neuroimage. 2004;23:1486-93.

22. Potenza MN. Neurobiology of gambling behaviors. Curr Opin Neurobiol. 2013;23:660-7.

23. Bechara A. Decision making, impulse control and loss of willpower to resist drugs: a neurocognitive perspective. Nat Neurosci. 2005;8:1458-63.

24. Brewer JA, Potenza MN. The neurobiology and genetics of impulse control disorders: relationships to drug addictions. Biochem Pharmacol. 2008;75:63-75.

25. Reuter J, Raedler T, Rose M, Hand I, Gläscher J, Büchel C. Pathological gambling is linked to reduced activation of the mesolimbic reward system. Nat Neurosci. 2005;8:147-8.

26. Limbrick-Oldfield EH, van Holst RJ, Clark L. Fronto-striatal dysregulation in drug addiction and pathological gambling: consistent inconsistencies? Neuroimage Clin. 2013;2:385-93. 
27. Blum K, Gull JG, Braverman ER, Comings DE. Reward deficiency syndrome. Am Sci. 1996;84:132-45.

28. Goldstein RZ, Volkow ND. Drug addiction and its underlying neurobiological basis: neuroimaging evidence for the involvement of the frontal cortex. Am J Psychiatry. 2002;159:1642-52.

29. Enoch M-A. The influence of gene-environment interactions on the development of alcoholism and drug dependence. Curr Psychiatr Rep. 2012;14:150-8.

30. Lin SAEN, Lyons MJ, Scherrer JF, Griffith K, True WR, Goldberg $\mathrm{J}$, et al. Familial influences on gambling behavior: an analysis of 3359 twin pairs. Addiction. 1998;93:1375-84.

31. Winters KC, Rich T. A twin study of adult gambling behavior. J Gambl Stud. 1998;14:213-25.

32. Beaver KM, Hoffman T, Shields RT, Vaughn MG, DeLisi M, Wright JP. Gender differences in genetic and environmental influences on gambling: results from a sample of twins from the National Longitudinal Study of Adolescent Health. Addiction. 2010;105:536-42.

33. Cilia R, van Eimeren T. Impulse control disorders in Parkinson's disease: seeking a roadmap toward a better understanding. Brain Struct Funct. 2011;216:289-99.

34. Cormier F, Muellner J, Corvol J-C. Genetics of impulse control disorders in Parkinson's disease. J Neural Transm. 2013;120:665-71.

35. Steeves TDL, Miyasaki J, Zurowski M, Lang AE, Pellecchia G, van Eimeren $\mathrm{T}$, et al. Increased striatal dopamine release in parkinsonian patients with pathological gambling: a $\left[{ }^{11} \mathrm{C}\right]$ raclopride PET study. Brain. 2009;132:1376-85.

36. Wang G-J, Volkow ND, Logan J, Pappas NR, Wong CT, Zhu W, et al. Brain dopamine and obesity. Lancet. 2001;357:354-7.

37. Kim SH, Baik S-H, Park CS, Kim SJ, Choi SW, Kim SE. Reduced striatal dopamine D2 receptors in people with Internet addiction. Neuroreport. 2011;22:407-11.

38. Clark L, Stokes PR, Wu K, Michalczuk R, Benecke A, Watson BJ, et al. Striatal dopamine $D_{2} / D_{3}$ receptor binding in pathological gambling is correlated with mood-related impulsivity. Neuroimage. 2012;63:40-6.

39. •• Boileau I, Payer D, Chugani B, Lobo D, Behzadi A, Rusjan PM, et al. The $\mathrm{D}_{2 / 3}$ dopamine receptor in pathological gambling: a positron emission tomography study with $\left[{ }^{11} \mathrm{C}\right]-(+)$-propyl-hexahydronaphtho-oxazin and $\left[{ }^{11} \mathrm{C}\right]$ raclopride. Addiction. 2013;108:953-63. This PET study looked at $D_{2}$ and $D_{3}$ receptor binding in patients with pathological gambling. Binding levels in the striatum were comparable with those in a control group, which stands in apparent contrast with the reward deficiency hypothesis and findings in pathological gambling in PD [35]. However, correlational findings still indicate a relationship between $D_{2} / D_{3}$ binding and impulsivity/ICDs.

40. •- O'Sullivan SS, Wu K, Politis M, Lawrence AD, Evans AH, Bose SK, et al. Cue-induced striatal dopamine release in Parkinson's disease-associated impulsive-compulsive behaviours. Brain. 2011;134:969-78. With use of raclopride PET, dopamine release following ICD-related cues was measured in PD patients with and without ICDs/compulsive use of dopaminergic drugs. There were no baseline differences, but patients with pathologic behavior showed increased dopamine release following relevant cues. As in [39], the results were not consistent with the reward deficiency hypothesis, but would be very much in line with the sensitization hypothesis.

41. Raymond NC, Grant JE, Kim SW, Coleman E. Treatment of compulsive sexual behaviour with naltrexone and serotonin reuptake inhibitors: two case studies. Int Clin Psychopharmacol. 2002;17:201-5.

42. Grant JE. Three cases of compulsive buying treated with naltrexone. Int J Psychiatry Clin Pract. 2003;7:223-5.

43. Grant JE, Kim SW. Medication management of pathological gambling. Minn Med. 2006;89:44-8.

44. Bosco D, Plastino M, Colica C, Bosco F, Arianna S, Vecchio A, et al. Opioid antagonist naltrexone for the treatment of pathological gambling in Parkinson disease. Clin Neuropharmacol. 2012;35:118-20.
45. Cools R, Nakamura K, Daw ND. Serotonin and dopamine: unifying affective, activational, and decision functions. Neuropsychopharmacology. 2011;36:98-113.

46. Kalivas PW, Volkow N, Seamans J. Unmanageable motivation in addiction: a pathology in prefrontal-accumbens glutamate transmission. Neuron. 2005;45:647-50.

47. Olive MF, Cleva RM, Kalivas PW, Malcolm RJ. Glutamatergic medications for the treatment of drug and behavioral addictions. Pharmacol Biochem Behav. 2012;100:801-10.

48. Tyacke RJ, Lingford-Hughes A, Reed LJ, Nutt DJ. GABA $A_{B}$ receptors in addiction and its treatment. Adv Pharmacol. 2010;58:373-96.

49. Dannon PN, Rosenberg O, Schoenfeld N, Kotler M. Acamprosate and baclofen were not effective in the treatment of pathological gambling: preliminary blind rater comparison study. Front Psychiatry. 2011;2:33.

50. Hicks CW, Pandya MM, Itin I, Fernandez HH. Valproate for the treatment of medication-induced impulse-control disorders in three patients with Parkinson's disease. Parkinsonism Relat Disord. 2011;17:379-81.

51. Schultz W. Potential vulnerabilities of neuronal reward, risk, and decision mechanisms to addictive drugs. Neuron. 2011;69:603-17.

52. Frank MJ. By carrot or by stick: cognitive reinforcement learning in parkinsonism. Science. 2004;306:1940-3.

53. Balodis IM, Kober H, Worhunsky PD, White MA, Stevens MC, Pearlson GD, et al. Monetary reward processing in obese individuals with and without binge eating disorder. Biol Psychiatry. 2013;73:877-86.

54. • Balodis IM, Kober H, Worhunsky PD, Stevens MC, Pearlson GD, Potenza MN. Diminished frontostriatal activity during processing of monetary rewards and losses in pathological gambling. Biol Psychiatry. 2012;71:749-57. This study demonstrates once again that hypoactivation of ventral PFC regions during gambling scenarios is a hallmark of pathological gambling. Together with [91], it suggests that ICDs-similarly to substance abuse - are accompanied by impaired response inhibition and salience attribution that is mediated by dopamine dysregulation .

55. van Eimeren T, Ballanger B, Pellecchia G, Miyasaki JM, Lang AE, Strafella AP. Dopamine agonists diminish value sensitivity of the orbitofrontal cortex: a trigger for pathological gambling in Parkinson's disease? Neuropsychopharmacology. 2009;34:2758-66.

56. Dong G, Huang J, Du X. Enhanced reward sensitivity and decreased loss sensitivity in Internet addicts: an fMRI study during a guessing task. J Psychiatr Res. 2011;45:1525-9.

57. Cavedini P, Riboldi G, Keller R, D’Annucci A, Bellodi L. Frontal lobe dysfunction in pathological gambling patients. Biol Psychiatry. 2002;51:334-41.

58. Goudriaan AE, Oosterlaan J, de Beurs E, van den Brink W. Decision making in pathological gambling: a comparison between pathological gamblers, alcohol dependents, persons with Tourette syndrome, and normal controls. Cogn Brain Res. 2005;23:137-51.

59. Danner UN, Ouwehand C, van Haastert NL, Hornsveld H, de Ridder DTD. Decision-making impairments in women with binge eating disorder in comparison with obese and normal weight women. Eur Eat Disord Rev. 2012;20:e56-62.

60. Linnet J, Møller A, Peterson E, Gjedde A, Doudet D. Inverse association between dopaminergic neurotransmission and Iowa Gambling Task performance in pathological gamblers and healthy controls. Scand J Psychol. 2011;52:28-34.

61. Power Y, Goodyear B, Crockford D. Neural correlates of pathological gamblers preference for immediate rewards during the Iowa Gambling Task: an fMRI study. J Gambl Stud. 2012;28:623-36.

62. Politis M, Loane C, Wu K, O'Sullivan SS, Woodhead Z, Kiferle L, et al. Neural response to visual sexual cues in dopamine treatmentlinked hypersexuality in Parkinson's disease. Brain. 2013;136:400-11.

63. Wang G-J, Geliebter A, Volkow ND, Telang FW, Logan J, Jayne $\mathrm{MC}$, et al. Enhanced striatal dopamine release during food stimulation in binge eating disorder. Obesity. 2011;19:1601-8. 
64. Goudriaan AE, De Ruiter MB, Van Den Brink W, Oosterlaan J, Veltman DJ. Brain activation patterns associated with cue reactivity and craving in abstinent problem gamblers, heavy smokers and healthy controls: an fMRI study. Addict Biol. 2010;15:491-503.

65. Crockford DN, Goodyear B, Edwards J, Quickfall J, el-Guebaly N. Cue-induced brain activity in pathological gamblers. Biol Psychiatry. 2005;58:787-95.

66. Sun Y, Ying H, Seetohul RM, Xuemei W, Ya Z, Qian L, et al. Brain fMRI study of crave induced by cue pictures in online game addicts (male adolescents). Behav Brain Res. 2012;233:563-76.

67. Choi J-S, Shin Y-C, Jung WH, Jang JH, Kang D-H, Choi C-H, et al. Altered brain activity during reward anticipation in pathological gambling and obsessive-compulsive disorder. PLoS ONE. 2012;7:e45938.

68. Holt DD, Green L, Myerson J. Is discounting impulsive?: evidence from temporal and probability discounting in gambling and nongambling college students. Behav Process. 2003;64:355-67.

69. Madden GJ, Petry NM, Johnson PS. Pathological gamblers discount probabilistic rewards less steeply than matched controls. Exp Clin Psychopharmacol. 2009; 17:283-90.

70. Voon V, Gao J, Brezing C, Symmonds M, Ekanayake V, Fernandez $\mathrm{H}$, et al. Dopamine agonists and risk: impulse control disorders in Parkinson's disease. Brain. 2011;134:1438-46.

71. Miedl SF, Peters J, Büchel C. Altered neural reward representations in pathological gamblers revealed by delay and probability discounting. Arch Gen Psychiatry. 2012;69:177-86.

72. Brand M, Kalbe E, Labudda K, Fujiwara E, Kessler J, Markowitsch HJ. Decision-making impairments in patients with pathological gambling. Psychiatry Res. 2005;133:91-9.

73. Svaldi J, Brand M, Tuschen-Caffier B. Decision-making impairments in women with binge eating disorder. Appetite. 2010;54:84-92.

74. Housden CR, O'Sullivan SS, Joyce EM, Lees AJ, Roiser JP. Intact reward learning but elevated delay discounting in Parkinson's disease patients with impulsive-compulsive spectrum behaviors. Neuropsychopharmacology. 2010;35:2155-64.

75. Alessi S, Petry N. Pathological gambling severity is associated with impulsivity in a delay discounting procedure. Behav Process. 2003;64:345-54.

76. MacKillop J, Amlung MT, Few LR, Ray LA, Sweet LH, Munafò MR. Delayed reward discounting and addictive behavior: a metaanalysis. Psychopharmacology (Berl). 2011;216:305-21.

77. Djamshidian A, Jha A, O'Sullivan SS, Silveira-Moriyama L, Jacobson $\mathrm{C}$, Brown P, et al. Risk and learning in impulsive and nonimpulsive patients with Parkinson's disease. Mov Disord. 2010;25:2203-10.

78. Voon V, Sohr M, Lang AE, Potenza MN, Siderowf AD, Whetteckey $\mathrm{J}$, et al. Impulse control disorders in parkinson disease: a multicenter case-control study. Ann Neurol. 2011;69:986-96.

79. Peters J, Büchel C. The neural mechanisms of inter-temporal decisionmaking: understanding variability. Trends Cogn Sci. 2011;15:227-39.

80. Aron AR. The neural basis of inhibition in cognitive control. Neuroscientist. 2007;13:214-28.

81. Verdejo-García A, Lawrence AJ, Clark L. Impulsivity as a vulnerability marker for substance-use disorders: review of findings from high-risk research, problem gamblers and genetic association studies. Neurosci Biobehav Rev. 2008;32:777-810

82. Voon V, Reynolds B, Brezing C, Gallea C, Skaljic M, Ekanayake V, et al. Impulsive choice and response in dopamine agonist-related impulse control behaviors. Psychopharmacology (Berl). 2009;207:645-59.

83. Thomsen KR, Joensson M, Lou HC, Møller A, Gross J, Kringelbach ML, et al. Altered paralimbic interaction in behavioral addiction. Proc Natl Acad Sci U S A. 2013. doi:10.1073/pnas.1302374110.

84. Forbush KT, Shaw M, Graeber MA, Hovick L, Meyer VJ, Moser DJ, et al. Neuropsychological characteristics and personality traits in pathological gambling. CNS Spectrums. 2008;13:306-15.

85. Potenza MN. An fMRI Stroop task study of ventromedial prefrontal cortical function in pathological gamblers. Am J Psychiatry. 2003; 160:1990-4.
86. Lawrence AJ, Luty J, Bogdan NA, Sahakian BJ, Clark L. Impulsivity and response inhibition in alcohol dependence and problem gambling. Psychopharmacology (Berl). 2009;207:163-72.

87. Dong G, Lu Q, Zhou H, Zhao X. Impulse inhibition in people with Internet addiction disorder: electrophysiological evidence from a Go/NoGo study. Neurosci Lett. 2010;485:138-42.

88. Dong G, DeVito EE, Du X, Cui Z. Impaired inhibitory control in 'internet addiction disorder': a functional magnetic resonance imaging study. Psychiatry Res Neuroimaging. 2012;203:153-8.

89. Djamshidian A, O'Sullivan SS, Lees A, Averbeck BB. Stroop test performance in impulsive and non impulsive patients with Parkinson's disease. Parkinsonism Relat Disord. 2011;17:212-4.

90. De Ruiter MB, Oosterlaan J, Veltman DJ, van den Brink W, Goudriaan AE. Similar hyporesponsiveness of the dorsomedial prefrontal cortex in problem gamblers and heavy smokers during an inhibitory control task. Drug Alcohol Depend. 2012;121: $81-9$.

91. • van Eimeren T, Pellecchia G, Cilia R, Ballanger B, Steeves TDL, Houle S, et al. Drug-induced deactivation of inhibitory networks predicts pathological gambling in PD. Neurology. 2010;75:1711-6. In this study, it was shown that dopamine agonists lead to ventral PFC deactivation only in those patients who developed ICDs while receiving dopaminergic drugs. Similarly to [54], this demonstrates that ICDs are characterized by impaired inhibitory control that is linked to dopamine dysregulation.

92. Cools R, Robbins TW. Chemistry of the adaptive mind. Philos Trans A Math Phys Eng Sci. 2004;362:2871-88.

93. Ersche KD, Roiser JP, Abbott S, Craig KJ, Müller U, Suckling J, et al. Response perseveration in stimulant dependence is associated with striatal dysfunction and can be ameliorated by a $\mathrm{D}_{2 / 3}$ receptor agonist. Biol Psychiatry. 2011;70:754-62.

94. Leeman RF, Potenza MN. Similarities and differences between pathological gambling and substance use disorders: a focus on impulsivity and compulsivity. Psychopharmacology (Berl). 2012;219:469-90.

95. De Ruiter MB, Veltman DJ, Goudriaan AE, Oosterlaan J, Sjoerds Z, van den Brink W. Response perseveration and ventral prefrontal sensitivity to reward and punishment in male problem gamblers and smokers. Neuropsychopharmacology. 2009;34:1027-38.

96. Buckholtz JW, Treadway MT, Cowan RL, Woodward ND, Li R, Ansari MS, et al. Dopaminergic network differences in human impulsivity. Science. 2010;329:532.

97. Kreek MJ, Nielsen DA, Butelman ER, LaForge KS. Genetic influences on impulsivity, risk taking, stress responsivity and vulnerability to drug abuse and addiction. Nat Neurosci. 2005;8: 1450-7.

98. Schinka JA, Letsch EA, Crawford FC. DRD4 and novelty seeking: results of meta-analyses. Am J Med Genet. 2002;114:643-8.

99. Reid RC, Carpenter BN, Spackman M, Willes DL. Alexithymia, emotional instability, and vulnerability to stress proneness in patients seeking help for hypersexual behavior. J Sex Marital Ther. 2008;34:133-49.

100. Bonnaire C, Bungener C, Varescon I. Alexithymia and gambling: a risk factor for all gamblers? J Gambl Stud. 2013;29:83-96.

101. Carano A, De Berardis D, Gambi F, Di Paolo C, Campanella D, Pelusi L, et al. Alexithymia and body image in adult outpatients with binge eating disorder. Int J Eat Disord. 2006;39:332-40.

102. Lombardo MV, Ashwin E, Auyeung B, Chakrabarti B, Lai M-C, Taylor K, et al. Fetal programming effects of testosterone on the reward system and behavioral approach tendencies in humans. Biol Psychiatry. 2012;72:839-47.

103. Voon V, Pessiglione M, Brezing C, Gallea C, Fernandez HH, Dolan $\mathrm{RJ}$, et al. Mechanisms underlying dopamine-mediated reward bias in compulsive behaviors. Neuron. 2010;65:135-42.

104. Goto Y, Otani S, Grace AA. The yin and yang of dopamine release: a new perspective. Neuropharmacology. 2007;53:583-7. 